\title{
Geoinformatics Study at the Czech Technical University in Prague
}

\author{
L. Mervart, A. Čepek
}

\begin{abstract}
At the CTU in Prague, there is a long tradition of master degree courses in geodesy, geodetic surveying and cartography. Taking into account the fast development of information technologies in recent decades, we decided to prepare a new study program that would combine computer science with a background of geodetic and cartographic know-how. Apart from other sources, our plans were inspired and influenced by the Review of Education Needs, a report prepared by Stig Enemark (Prague 1998), and by our experience from several Virtual Academy workshops.

We have decided to call this program „Geoinformatics“ to emphasize the role of computer technologies in collecting, analyzing and exploiting information about our planet. Within this presentation we will explain the basic ideas behind our new study program and emphasize the features that distinguish it from classical geodetic or cartographic programs. We will mention the connection between our new study program and several geodetic and software projects running at our institute - software development for real-time GPS applications, cooperation with the Astronomical Institute, University of Berne, on the development of so-called Bernese GPS Software, the GNU project Gama for adjustment of geodetic networks, etc.
\end{abstract}

Keywords: key education, curricula, geoinformation, software development.

\section{What's in a name?}

What's in a name? That which we call a rose

By any other word would smell as sweet.

(Romeo and Juliet - Act II, Scene II)

We dare to disagree with the great poet. The name of a study program can be important for students finishing their high school and deciding which university they want to apply to. Let us make a tiny linguist digression. According to [1], Geodesy is the scientific discipline that deals with measurement and representation of the earth, its gravitational field and geodynamic phenomena (polar motion, earth tides, and crustal motion) in three-dimensional time varying space. The second branch of our traditional study programs, Cartography, is (according to [1] again) the study and practice of making maps or globes. We find these definitions good, but do they reveal that computer science and informatics nowadays play a key role in our discipline? This question can be important for young people deciding about the direction of their future professional career.

A new word, Geomatics, was apparently coined by B. Dubuisson in 1969. It is the discipline of gathering, storing, processing, and delivering geographic information. This broad term applies to both science and technology, and integrates several specific disciplines (including geodesy, cartography, and, last but not least, geographic information systems). We were tempted to call our study program "Geomatics", however, at the end we voted for another new word - Geoinformatics.

Informatics (or Information Science) is studied as a branch of computer science and information technology and is related to database, ontology and software engineering. It is primarily concerned with the structure, creation, management, storage, retrieval, dissemination and transfer of information. We understand "Geoinformatics" as a science that synthetizes the achievments of informatics with knowledge of the principles of geodesy and cartography. In the geodetic courses we will teach our students the mathematical and physical backgrounds of geodesy as well as the practise of surveying - the techniques of gathering and processing mea- surements. Within the study of geoinformatics we will teach our students the theoretical principles of geodesy and many things about computers and information technologies.

\section{Our projects - geodesy and computer science in concordance}

Protest my ears were never better fed

With such delightful pleasing harmony.

(Pericles, Prince of Tyre - Act II, Scene V)

We have studied geodesy and we like sitting at computers writing our own applications. Can we bring these two things into concordance? We are deeply convinced that we can. We will present some of our projects to demonstrate the interrelations between geodesy and informatics.

\subsection{Real-Time monitoring of GPS networks}

The first project is related to our work for the company GPS Solutions, Boulder, USA. Within the contract between GPS Solutions and the Japanese Geographical Survey Institute (GSI) we take part in the development of a program system for real-time processing of GPS data with the highest possible accuracy [8]. Together with our American colleagues we have prepared a software system consisting of a server that collects data from many GPS receivers and the RTNET (Real-Time NETwork) processing program, which computes very accurate positions of GPS stations in real time. The system is primarily designed for the real-time processing of data stemming from the Japanese network GEONET (GPS Earth Observation NETwork) - a unique network consisting of 1200 permanent GPS stations. One of the main purposes of GEONET is to monitor seismic deformations. Understanding the character of seismic waves and the laws of their propagation may help in the design of earthquake-resistant buildings or even the establishment of an alert system that could save human lives. The left-hand side of the Fig. 2 shows a map of several GEONET stations located on the southern coast of Hokkaido Island. The right-hand side shows the motion of these stations during the Tokachi-Oki earth- 

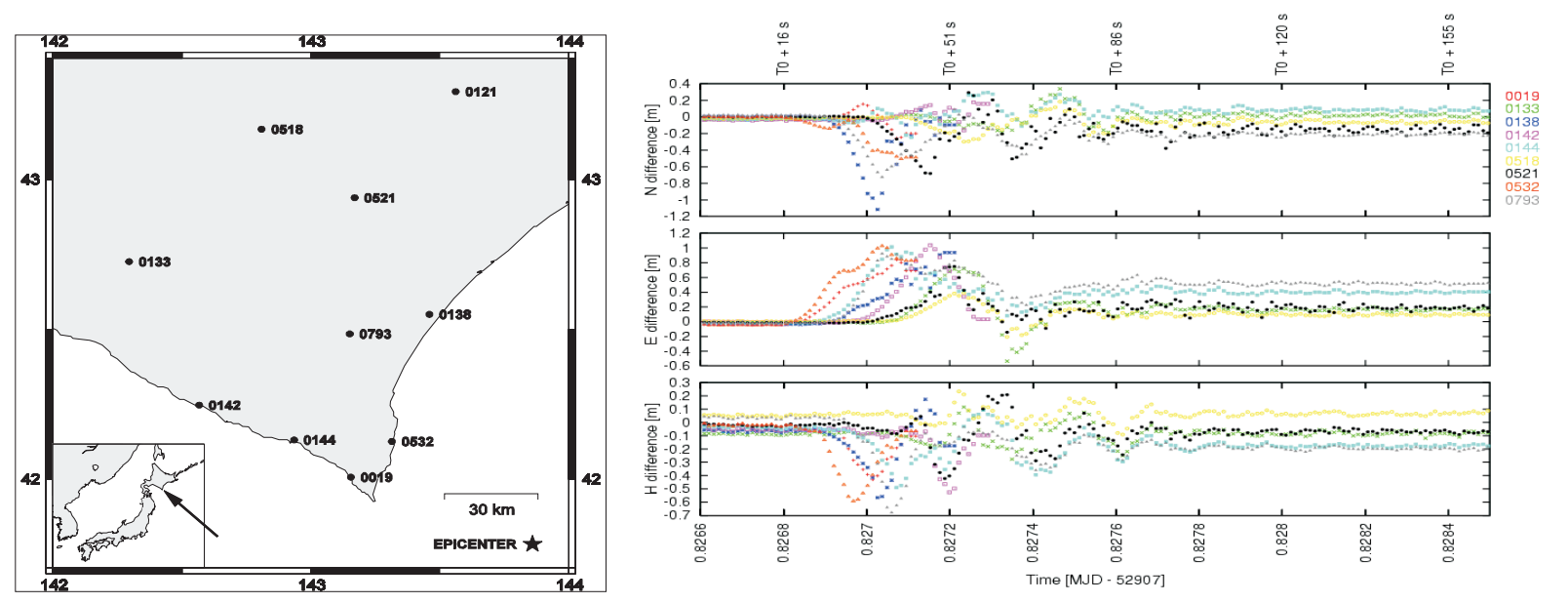

Fig. 1

Fig. 1

quake on September $26^{\text {th }}, 2003$, computed, by our RTNET software.

We find it fascinating to see the huge seismic shocks revealed by GPS measurements. The plot clearly shows the propagation of seismic waves - stations closer to the epicenter sense the waves earlier than the more distant stations. The time delay between the so-called primary and secondary seismic waves can be observed by comparing the horizontal and vertical components of the station motions.

\subsection{Bernese GPS software}

We are very proud to have the opportunity to take part in the development of the so-called Bernese GPS Software. This software package has been developed at the Astronomical Institute, University of Berne, Switzerland since the 1980s. It is used at many institutions round the globe for post-processing GPS data with the highest accuracy and for various other purposes - the software is capable to estimate a large number of different kinds of parameters: station coordinates, earth rotation parameters, satellite orbits, parameters of the atmosphere, etc. The software is recognized for the quality of its mathematical model, which ensures the accuracy of the results. It is the know-how of geodesy and celestial mechanics that stands behind the software's success. However, we are convinced that the technical quality of the program, its availability on different computer platforms, and a given level of user-friendliness are of major importance, too.

The Fig. 2 shows a window of the Bernese menu system. The Bernese GPS Software is an example of the concordance between geodesy and informatics. It is becoming usual nowadays that many mathematical achievements find their "materialization" in sophisticated software projects.

\subsection{GNU Gama and other free software projects}

Talking about software development, Free Software, a specific software area, is one of the fields that we want our students to get involved in. In order to learn more about the phenomenon of Free Software, selected essays of Richard M. Stallman are probably the best starting point (or one can read the interview [7]).

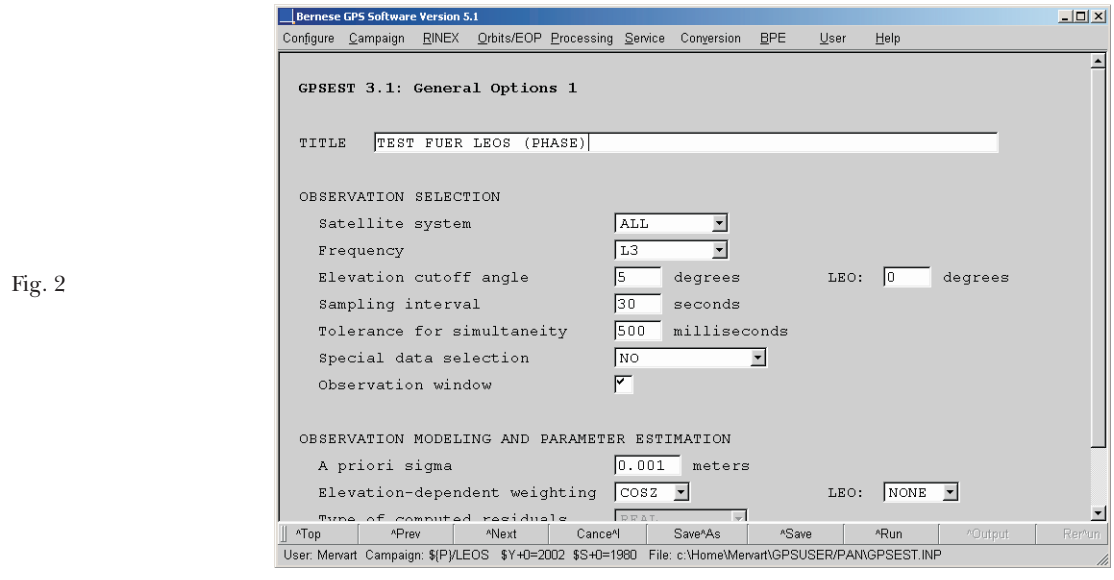

Fig. 2 
Our first major free software project GNU Gama is dedicated to adjustment of geodetic networks. It has been presented at various FIG meetings ([3], [4]), so we need not describe it in detail here. The beginning of the Gama project was influenced by our experience from Virtual Academy meetings, where it was first presented as a project aimed at motivating our students to get involved in software development and international collaboration.

Another example of our free software projects was presented last year at the FIG Working Week in Athens [5]. The software part of this project was the GPS observation database written by Jan Pytel in close collaboration with Prof. Kostelecky, and this year we will extend our collaboration to a project to adjust combined solutions from various observation techniques (GPS, VLBI, etc).

We believe that the new courses on geoinformatics, with an intensive focus on the theoretical background, will help us to attract more talented students, who will be able to collaborate on software projects of a scientific nature, as described above.

\section{The future of geodetic science}

To-morrow, and to-morrow, and to-morrow,

Creeps in this petty pace from day to day.

(Macbeth - Act V, Scene V)

From Macbeth's point of view, time seems to have passed slowly. Nowadays we know the relativistic effects: for people planning the future of their educational facilities time may run faster than they wish. Our present-day today's knowledge may appear insufficient for tomorrow's needs. How should we deal with this situation? What knowledge will our students need in several years after they have graduated? What should we teach them? This is not an easy question. Taking into account our inability to estimate the precise needs of the future, we are convinced that we have to concentrate on teaching methods, ways of thinking, and general theories rther then specialized topics. Our students should primarily be able to gather and analyze information. And this is actually the bottom line of geoinformatics. Without knowledge of our primary science - geodesy - the most breathtaking informatics achievements are useless for us. But, conversely, our discipline (like any modern science) cannot develop without sophisticated information processing. It cannot live without informatics.

From the practical point of view we had, first of all, to follow the framework of bachelor/master degree programs at the faculty of Civil Engineering, where bachelor programs last 8 semesters and master degree programs last three semesters. To distinguish clearly between our bachelors and masters, we decided that bachelors should typically be professional users of geoinformatic systems, in contrast to masters, who should become developers, analysists and leading managers of geoinformation systems.

One of the major information systems in the Czech Republic is the Cadastral Information system. When preparing the bachelor curricula, we decided that education in the Cadastre should be given in the same full level as in the existing study branch in geodesy and cartography. Another strategic decision was that our bachelors should be prepared for managerial skills, and thus we put substantial emphasis on education in the social sciences. The definition of the structure of the new social science courses was fully in the competence of the head of our department of social sciences, doc. Václav Liška.

With the focus on our main strategic priorities

- mathematics

- social sciences and management

- geodesy

- applied informatics

the courses offered for the bachelor degree program are summarized in the Table 1.

Table 1

\begin{tabular}{|l|c|l|c|}
\hline Course & Sem. & Course & Sem. \\
\hline Calculus 1 & 1 & Calculus 2 & 2 \\
\hline Technical geodesy & 1 & Constructive geometry & 2 \\
\hline OS Linux & 1 & Foreign language & 2 \\
\hline Foreign language & 1 & Technical geodesy & 2 \\
\hline Introduction to law & 1 & Database systems & 2 \\
\hline Physics 1 & 1 & Rhetoric & 2 \\
\hline Introduction to numerical mathematics & 1 & Physics & 2 \\
\hline Calculus 3 & 3 & Calculus 4 & 4 \\
\hline Introduction to economics & 3 & Psychology and sociology & 4 \\
\hline Theoretical geodesy 1 & 3 & Theoretical geodesy 2 & 4 \\
\hline Theory of errors and adjustment 1 & 3 & Theory of errors and adjustment 2 & 4 \\
\hline Programming language C++ & 3 & Project - Informatics & 4 \\
\hline Environmental engineering & 3 & Mathematical cartography & 4 \\
\hline Practical training in surveying & 3 & Foreign language & 4 \\
\hline
\end{tabular}




\begin{tabular}{|l|c|l|c|}
\hline Course & Sem. & Course & Sem. \\
\hline Photogrammetry and remote sensing 1 & 5 & Photogrammetry and remote sensing 2 & 6 \\
\hline Probability and math. statistics & 5 & Cadastre & 6 \\
\hline GIS 1 & 5 & GIS 2 & 6 \\
\hline Mapping & 5 & WWW services & 6 \\
\hline Project - Geodesy & 5 & Engineering geodesy & 6 \\
\hline Real estate law & 5 & Electives (4 credits) & 6 \\
\hline Management psychology & 5 & & \\
\hline Optimization methods & 7 & Elective courses $(16$ credits) & 8 \\
\hline Information systems & 7 & Bachelor diploma work & 8 \\
\hline Image data processing & 7 & & \\
\hline Topograph.and thematical cartography & 7 & & \\
\hline Ethics & 7 & & \\
\hline Elective courses (4 credits) & 7 & & \\
\hline Pre-diploma project & 7 & & \\
\hline
\end{tabular}

Each bachelor student is required to choose from 25 elective subjects starting from the sixth semester.

The courses offered for the master degree program in geoinformatics are in Table 2.

Table 2

\begin{tabular}{|l|c|l|c|}
\hline Course & Sem. & Course & Sem. \\
\hline Graph Theory & 1 & Numerical Mathematics & 2 \\
\hline Object-Oriented Programming & 1 & Project-Statistics & 2 \\
\hline Statistics-Robust Methods & 1 & Project-Professional Specialization & 2 \\
\hline Elective Courses (12 credits) & 1 & Elective Courses (14 credits) & 2 \\
\hline Social sciences and management & 3 & & \\
\hline Elective courses (4 credits) & 3 & & \\
\hline Diploma project & 3 & & \\
\hline
\end{tabular}

The compulsory courses in the master degree program are accompanied by the offer of 36 elective courses ranging from Tensor calculus and Mathematical modeling to Space and physical geodesy or Combinatorial optimization.

We expect most of our bachelors to continue their studies at master degree level. Our program is designed on the basis of this presumption. However, our goal is also to open the new study branch to other fields, namely to geaduates of other bachelor programs at our faculty, e.g., Environmental Engineering or the existing study branch Geodesy and Cartography

Geoinformatics

Geodesy and Cartography

Geoinformatics $\leftrightarrows$ Environmental Engineering

(or Water Engineering and Water Structures)

System Engineering in the Building Industry (IT)

In June 2005 the Czech Ministry of Education, Youth and Sports approved our new curricula, and the first semester in geoinformatics will be opened in 2006. The first semester of the master degree program in geoinformatics will open in 2007. One of our next steps will be to fully harmonize the first two years of the programs in geodesy and cartography with the new geoinformatics study plan.

\section{References}

[1] Vaníček, P., Krakiwski, E. J.: Geodesy: the Concepts, North-Holland, 1986, $2^{\text {nd }}$ ed., ISBN 0444877754.

[2] Enemark, S.: "Review of Education Needs", Consultancy to the Czech Office for Surveying, Mapping and Cadastre, EU Phare Land Registration Project, Project No CZ 94402-02, February 1998.

[3] Čepek, A., Pytel, J.: "Free Software - An Inspiration for a Virtual Academy.” FIG XXII International Congress, Washington, D.C. USA, April 19-26, 2002.

[4] Čepek, A., Pytel, J.: "Acyclic Visitor Pattern in Formulation of Mathematical Model." FIG Working Week, Athens, Greece, May 22-27, 2004. 
[5] Kostelecký, J., Pytel, J.: "Modern Geodetic Control in the Czech Republic Based on Densification of EUREF Network", FIG Working Week, Athens, Greece, May 22-27, 2004.

[6] Stallman, R. M.: Free Software, Free Society (selected essays), GNU Press, Free Software Foundation, Boston, MA USA, ISBN 1-882114-98-1

[7] Stallman, R. (interview): http://kerneltrap.org/node/4484

[8] Rocken, C., Mervart, L., Luke, Z., Johnson, J., Kanzaki M.: "Testing a New Network RTK Software System." In: Proceedings of GNSS 2004. Institute of Navigation, Fairfax, 2004, 2831-2839.

[9] http://geoinformatika.fsv.cvut.cz/akreditace/ archive of all accreditation documents submitted to the Czech Ministry of Education, Youth and Sports.
Prof. Dr. Ing. Leoš Mervart, DrSc. phone: +420224354805 fax: +420224354343 e-mail: mervart@fsv.cvut.cz

\section{Department of Geodesy}

Prof. Ing. Aleš Čepek, CSc. phone: + 420224354647 fax: +420224355419

e-mail:cepek@fsv.cvut.cz Web site: http://gama.fsv.cvut.cz/ cepek

Department of Mapping and Cartography

Czech Technical University in Prague

Faculty of Civil Engineering

Thákurova 7

16629 Prague 6, Czech Republic 